\title{
Synthesis Tetrathioarsenate as a Precipitant of Ammoniate Ions of Transitional Metals
}

\author{
I. Didbaridze ${ }^{1, ~ *}$, M. Rusia $^{2}$, K. Rukhaia ${ }^{3}$ \\ ${ }^{1}$ Kutaisi Technical University, Kutaisi, Georgia \\ ${ }^{2}$ Chemical LAB, Ivane Javakhishvili Tbilisi State University, Tbilisi, Georgia \\ ${ }^{3}$ Private Sector-led Recycling Component Leader Waste Management Technologies in Regions Caucasus Environmental NGO Network \\ (CENN), Georgia
}

\section{Email address:}

maiarusia@mail.ru (M. Rusia)

\section{To cite this article:}

I. Didbaridze, M. Rusia, K. Rukhaia. Synthesis and Study of Tetrathioarsenates of d10-Metals. Earth Sciences. Special Issue: Engineering Seismology: An Interface Between Earthquake Science and Practical Engineering. Vol. 4, No. 5-1, 2015, pp. 88-90.

doi: $10.11648 /$ j.earth.s.2015040501.26

\begin{abstract}
Synthesized substances obtained by sodium tetrathioarsenate reaction with silver(I), cobalt (II), mickelous (II), copper (II), zincous, cadmium and mercury have been studied by IR-spectroscopy, X-ray analysis.
\end{abstract}

Keywords: Tetrathioarsenate, Transitional Metals

\section{Introduction}

Absolute majority of transition metals amiacates are water-soluble complexes. Therefore their separation in individual state needs concentration by evaporation till obtaining saturated solution or re-precipitation with some solvent, that is rather difficult [1].

On the other hand, synthesis conditions of transition metals tetraoxoarsenates and their physical-chemical properties are rather well investigated [2], but data about tetrathioarsenates are limited enough [3-5]. As for d-metals application of tetrathioarsenates for obtaining corresponding coordinative compounds, we don't have any data about them.

The goal of the present work is to solve the following problems: 1) to establish the possibility of using tetrathioarsenates of alkaline metals as precipitants of ammoniate ions of transitional metals form aqueous solutions; 2) in case if the experiment is a success to study the products of reaction by chemical and physico-chemical methods and in this way to establish the mechanism of characteristic changes in new synthesized coordinative compounds in relation with the change of central atom.

\section{Research Methods}

Silver (I) and mercury (II) nitrates, nickel (II) and cobalt (II) chlorides, zinc and cadmium acetates and copper (II) sulphide were used as initial substances and sodium tetrathioarsenate as a precipitant, which was obtained by the equation [1]:

$3 \mathrm{Na}_{2} \mathrm{~S}+\mathrm{As}_{2} \mathrm{~S}_{3}+2 \mathrm{~S}+16 \mathrm{H}_{2} \mathrm{O} \rightarrow 2 \mathrm{Na}_{3} \mathrm{AsS}_{4} \cdot 8 \mathrm{H}_{2} \mathrm{O}$

The experiment was carried out in the following way: first the ammoniates of transitional (d-elements) metals were obtained by the action of ammonium alkali in the appropriate water-soluble salts, then the reaction product (without isolating in the individual state) was treated by sodium tetrathioarsenate solution in the same aqueous solution. Tetrathioarsenate ammoniates of d-metals were precipitated immediately according to the following consecutive reactions:

$\mathrm{AgNO}_{3}+2 \mathrm{NH}_{4} \mathrm{OH} \rightarrow\left[\mathrm{Ag}\left(\mathrm{NH}_{3}\right)_{2}\right] \mathrm{NO}_{3}+2 \mathrm{H}_{2} \mathrm{O}$

$\mathrm{MX}_{2}+\mathrm{nNH}_{4} \mathrm{OH} \rightarrow\left[\mathrm{M}\left(\mathrm{NH}_{3}\right)_{\mathrm{n}}\right] \mathrm{X}_{2}+\mathrm{nH}_{2} \mathrm{O}$

$3\left[\mathrm{Ag}\left(\mathrm{NH}_{3}\right)_{2}\right] \mathrm{NO}_{3}+\mathrm{Na}_{3} \mathrm{AsS}_{4} \rightarrow\left[\mathrm{Ag}\left(\mathrm{NH}_{3}\right)_{2}\right]_{3} \mathrm{AsS}_{4} \downarrow+3 \mathrm{NaNO}_{3}$

$3\left[\mathrm{M}\left(\mathrm{NH}_{3}\right)_{\mathrm{n}}\right] \mathrm{X}_{2}+2 \mathrm{Na}_{3} \mathrm{AsS}_{4} \rightarrow\left[\mathrm{M}\left(\mathrm{NH}_{3}\right)_{\mathrm{n}}\right]_{3}\left(\mathrm{AsS}_{4}\right)_{2} \downarrow+6 \mathrm{NaX}$ where $\mathrm{M}=\mathrm{Zn}, \mathrm{Cd}, \mathrm{Hg}, \mathrm{Cu}$ or $\mathrm{Ni} ; \mathrm{X}=\mathrm{CH}_{3} \mathrm{COO}, \mathrm{NO}_{3}, \mathrm{Cl}$ or $1 / 2 \mathrm{SO}_{4}, \mathrm{n}=4$ or 6 .

All attempts to obtain tetrathioarsenate ammoniate of cobalt (II) in analogous way were unsuccessful. Cobalt (II0 is found to be easily oxidized by atmospheric oxygen in ammonium alkaline solution. Therefore, we decided to make use of this fact to obtain tetrathioarsenate of cobalt (III). It can be achieved by the following consecutive reactions:

a) $4 \mathrm{CoCl}_{2} \cdot 6 \mathrm{H}_{2} \mathrm{O}+4 \mathrm{NH}_{4} \mathrm{Cl}+2 \mathrm{NH}_{4} \mathrm{OH}+\mathrm{O}_{2} \rightarrow 4\left[\mathrm{Co}\left(\mathrm{NH}_{3}\right)_{6}\right] \mathrm{Cl}_{3}$ $+26 \mathrm{H}_{2} \mathrm{O}$

b) $4\left[\mathrm{Co}\left(\mathrm{NH}_{3}\right)_{6}\right] \mathrm{Cl}_{3}+4 \mathrm{Na}_{3} \mathrm{AsS}_{4} \cdot 8 \mathrm{H}_{2} \mathrm{O} \rightarrow\left[\mathrm{Co}\left(\mathrm{NH}_{3}\right)_{6}\right] \mathrm{AsS}_{4}+$ $6 \mathrm{NaCl}+\mathrm{H}_{2} \mathrm{O}$ totally 
$2 \mathrm{CoCl}_{2} \cdot 6 \mathrm{H}_{2} \mathrm{O}+2 \mathrm{NH}_{4} \mathrm{Cl}+10 \mathrm{NH}_{4} \mathrm{OH}+2 \mathrm{Na}_{3} \mathrm{AsS}_{4} \cdot 8 \mathrm{H}_{2} \mathrm{O}$ $\rightarrow 2\left[\mathrm{Co}\left(\mathrm{NH}_{3}\right)_{6}\right] \mathrm{AsS}_{4}+6 \mathrm{NaCl}+39 \mathrm{H}_{2} \mathrm{O}$

Elementary analysis of synthesized substances was carried out by the well-known methods: arsenic was defined by the method of Ewins [2], sulphur by gravimetric.
Load of initial substances and yield of obtained products are presented in Table 1 and the results of chemical analysis of synthesized substances in Table 2.

Table 1. Load of Starting substances and yield of obtained products

\begin{tabular}{|c|c|c|c|c|c|c|c|c|c|}
\hline & \multicolumn{6}{|c|}{ Load of starting materials } & \multirow{2}{*}{\multicolumn{3}{|c|}{ yield of obtained products }} \\
\hline & \multirow{2}{*}{$\begin{array}{l}\text { salt } \\
\text { formula } \\
\end{array}$} & \multirow[b]{2}{*}{ g } & \multirow[b]{2}{*}{ mole } & \multirow{2}{*}{\begin{tabular}{|l|} 
ammonia \\
solution $(\mathrm{ml})$ \\
\end{tabular}} & \multicolumn{2}{|c|}{$\mathrm{Na}_{3} \mathrm{AsS}_{4} \cdot 8 \mathrm{H}_{2} \mathrm{O}$} & & & \\
\hline & & & & & g & mole & g & mole & $\%$ \\
\hline II & $\mathrm{CuSO}_{4} \cdot 5 \mathrm{H}_{2} \mathrm{O}$ & 2.70 & 0.0108 & 20.0 & 3.0 & 0.0072 & 2.72 & 0.0034 & 94.4 \\
\hline III & $\mathrm{Zn}\left(\mathrm{CH}_{3} \mathrm{COO}\right)_{2} \cdot 2 \mathrm{H}_{2} \mathrm{O}$ & 2.37 & 0.0108 & 16.0 & 3.0 & 0.0072 & 2.48 & 0.0031 & 85.8 \\
\hline IV & $\mathrm{Cd}\left(\mathrm{CH}_{3} \mathrm{COO}\right)_{2} \cdot 2 \mathrm{H}_{2} \mathrm{O}$ & 2.50 & 0.0107 & 16.0 & 3.0 & 0.0072 & 3.10 & 0.0033 & 90.9 \\
\hline VI & $\mathrm{NiCl}_{2} \cdot 6 \mathrm{H}_{2} \mathrm{O}$ & 2.57 & 0.0108 & 18.0 & 3.0 & 0.0072 & 2.84 & 0.0032 & 88.5 \\
\hline VII & $\mathrm{CoCl}_{2} \cdot 6 \mathrm{H}_{2} \mathrm{O}$ & 2.58 & 0.0108 & 18.0 & 3.0 & 0.0072 & 3.16 & 0.0035 & 96.3 \\
\hline
\end{tabular}

Table 2. The results of chemical analysis of synthesized compounds

\begin{tabular}{|c|c|c|c|c|c|c|c|c|c|c|}
\hline & \multirow{2}{*}{ Compound } & \multirow{2}{*}{ Colour } & \multicolumn{4}{|c|}{ Found, $\%$} & \multicolumn{4}{|c|}{ Calculated, $\%$} \\
\hline & & & M & As & $\mathbf{N}$ & $\mathbf{S}$ & $\mathbf{M}$ & As & $\mathbf{N}$ & $\mathbf{S}$ \\
\hline I & {$\left[\mathrm{Ag}\left(\mathrm{NH}_{3}\right)_{2}\right]_{3} \mathrm{AsS}_{4}$} & black & 51.38 & 11.84 & 13.48 & 20.47 & 51.51 & 11.92 & 13.96 & 20.35 \\
\hline II & {$\left[\mathrm{Cu}\left(\mathrm{NH}_{3}\right)_{4}\right]_{3}\left(\mathrm{AsS}_{4}\right) 2$} & ligh grey & 23.88 & 18.56 & 21.07 & 31.87 & 23.79 & 18.74 & 20.48 & 31.98 \\
\hline III & {$\left[\mathrm{Zn}\left(\mathrm{NH}_{3}\right)_{4}\right]_{3}\left(\mathrm{AsS}_{4}\right)_{2}$} & white & 24.76 & 18.54 & 20.97 & 31.44 & 24.34 & 18.61 & 20.84 & 31.76 \\
\hline IV & {$\left[\mathrm{Hg}\left(\mathrm{NH}_{3}\right)_{4}\right]_{3}\left(\mathrm{AsS}_{4}\right)_{2}$} & black & 49.52 & 12.23 & 13.92 & 21.24 & 49.66 & 12.98 & 13.86 & 21.13 \\
\hline $\mathrm{V}$ & {$\left[\mathrm{Cd}\left(\mathrm{NH}_{3}\right)_{4}\right]_{3}\left(\mathrm{AsS}_{4}\right)_{2}$} & yellow & 35.48 & 15.72 & 17.86 & 27.18 & 35.60 & 15.84 & 17.74 & 27.03 \\
\hline VI & {$\left[\mathrm{Ni}\left(\mathrm{NH}_{3}\right)_{6}\right]_{3}\left(\mathrm{AsS}_{4}\right)_{2}$} & ligh green & 19.98 & 16.76 & 28.46 & 28.74 & 19.83 & 16.89 & 28.38 & 28.83 \\
\hline VII & {$\left[\mathrm{Co}\left(\mathrm{NH}_{3}\right)_{6}\right]_{3}\left(\mathrm{AsS}_{4}\right)_{2}$} & orange & 19.82 & 16.74 & 28.50 & 28.96 & 19.61 & 16.87 & 28.35 & 28.80 \\
\hline
\end{tabular}

\section{Main Results}

\subsection{Constitution and Structure of Synthesized Substances}

Synthesized complexes are fine crystalline substances, which are practically insoluble on water or any other organic solvents. The have not a definite melting point and by heating above $150^{\circ} \mathrm{C}$ they are decomposed. They are insoluble in alkalis except $\left[\mathrm{Zn}\left(\mathrm{NH}_{3}\right)_{4}\right]_{3}\left(\mathrm{AsS}_{4}\right)_{2}$. Their reaction with acids $\left(\mathrm{HCl}, \mathrm{H}_{2} \mathrm{SO}_{4}\right)$ is a complex process and requires to be studied separately. We can make a foregone conclusion that one of the products of reaction is arsenic $(\mathrm{V})$ sulphide. Their reaction with concentrated nitrous acid is the exception when $\mathrm{As}_{4} \mathrm{~S}_{10}$ is changed.

Constitution and structure of synthesized substances is confirmed by the data of IR-spectroscopy and roentgen-phase studies, apart from the chemical analysis.

Study of IR-spectra of the substances under consideration shows that in every sample there are noted bands of $470 \mathrm{~cm}^{-1}$ deformative vibration characteristic to $-\mathrm{As}-\mathrm{S}$ bond [4] and the bands of valency vibration are noted at $430 \mathrm{~cm}^{-1}$ regions [6]. Bands at $1610 \mathrm{~cm}-1$ and $3150 \mathrm{~cm}-1$ region belonging to modified deformative and valency vibrations of coordinated ammonium respectively, allow us to conclude that the obtained compounds are ammoniates of d-metals [7].

Individuality of products is conformed by roentgen-phase analysis as well as ---- relation with the change of cation. It was shown by various roentgen reflexions and their distribution.

\subsection{Synthesis of $\left[\mathrm{Ag}\left(\mathrm{NH}_{3}\right)_{2}\right]_{3} \mathrm{AsS}_{4}$}

Saturated solution of $3.0 \mathrm{~g}$ ( 0.0176 mole $)$ silver (I) nitrate was added by excess amount of alkyl ammonium until the first formed precipitation was dissolved. The solution obtained was treated with $2.45 \mathrm{~g}$ ( 0.0059 mole $)$ of saturated solution of sodium tetrathioarsenate with constant stirring. Some black substance was precipitated at once. It was hold in the mother solution to be formed into crystal substance. Next day the flask contents was filtered and washed with water and alcohol. After drying it under the air $3.20 \mathrm{~g}$ (0.0051 mole) of $\left[\mathrm{Ag}\left(\mathrm{NH}_{3}\right)_{2}\right]_{3} \mathrm{AsS}_{4}$ was obtained i.e. $86.4 \%$ of the theoretical.

Other ammoniate complexes were also obtained analogously except $\left[\mathrm{Co}\left(\mathrm{NH}_{3}\right)_{6}\right] \mathrm{AsS}_{4}$.

\subsection{Synthesis of $\left[\mathrm{Co}\left(\mathrm{NH}_{3}\right)_{6}\right] \mathrm{AsS} \mathrm{S}_{4}$}

Mixture of $\mathrm{CoCl}_{2} \cdot 6 \mathrm{H}_{2} \mathrm{O}(3.0 \mathrm{~g})$ and $\mathrm{NH}_{4} \mathrm{Cl}(2.0 \mathrm{~g})$ was dissolved in water $(25 \mathrm{ml})$. The solution was added by $0.1 \mathrm{~g}$ of activated carbon, $15.0 \mathrm{ml}$ of concentrated ammonium alkali and a strong stream of air was let into it until the solution changed from red into yellowish-brown. The flask content was filtered and added by saturated solution of $2.0 \mathrm{~g}(0,0048$ mole) of $\mathrm{Na}_{3} \mathrm{AsS}_{4} \cdot 8 \mathrm{H}_{2} \mathrm{O}$ with constant stirring. The small-crystal substance of dark orange color precipitated at once. Next day it was filtered, washed with the diluted solution of ammonia and dried out in vacuum desiccators on water -free alkaline kalium until a permanent mass was obtained. In the result $2.0 \mathrm{~g}(0.0042$ mole $)$ of $\left[\mathrm{Co}\left(\mathrm{NH}_{3}\right)_{6}\right] \mathrm{AsS}_{4}$ was obtained, i.e. $98.5 \%$ of the theoretical. 


\section{Conclusion}

Thus, studies have shown that by treatment of silver (I), mercury (II), zinc, cadmium, copper (II), nickel (II) and cobalt (III) amiacates with sodium tetrathioarsenates without their separation in individual condition, exchange reaction takes place by formation corresponding complexes. Obtained complex compounds are cationic-complexes, and tetrathioarsenat-ion is located in the outer sphere.

There are certain regularity by thermal decomposition of obtained compounds. That is reflected above all in extracting of ligand - ammonia, following dethionating and removing arsenic in sulfide form (realgar).

\section{References}

[1] Basalo F., Jonson R. Chemistry of coordinative compounds. M., Mir, 1996, $273 \mathrm{p}$.

[2] Makhmetov M.J., Gorokhova L.G. Thermal stability of arsenates. Alma-Ata, Nauka, Kazakhskaia SSR, 1998, 109 p.

[3] Palazzi M. Sur les thioarsenates de sodium. VII. Preparation et deshydratation de $\mathrm{Na} 3 \mathrm{AsO} 2 \mathrm{~S} 2 \cdot 11 \mathrm{H} 2 \mathrm{O}, \mathrm{Na} 3 \mathrm{AsO} 2 \mathrm{~S} 2 \cdot 2 \mathrm{H} 2 \mathrm{O}$, $\mathrm{Na} 3 \mathrm{AsO} 2 \mathrm{~S} 2$. Evolution thermique de $\mathrm{Na} 3 \mathrm{AsO} 2 \mathrm{~S} 2$ dans dofferentes atmospheres //Bull. Soc. Chim. France. 1972. v. 5, p. $1172-1176$.

[4] Palazzi M. Sur les thioarsenates et thiophosphates de sodium.
IX. Preparation, deshydratation et etude radiocristallographique de $\mathrm{Na} 3 \mathrm{AsO} 3 \mathrm{~S} \cdot 11 \mathrm{H} 2 \mathrm{O}$ et Na3POS3·11H2O //Bull. Soc. Chim. France. 1973. v. 3, part I, 845-850.

[5] Palazzi M., Guerin H. Sur de nouveaux arseniates de nickel et de cobalt // Bull. Soc. Chim. France. 1978. part I, №3-4, p. 845-850.

[6] Masson J. Sur les arseniates de stroncium//Compt. rend. 1977, c.285, №12. pp. 389-392.

[7] Charles-Messance B., Duc Mauge C., Guerin H. Sur les arseniates de cobalt// Compt. rend. 1960, №3. pp. 2216-2217.

[8] Charles-Messance B., Duc Mauge C., Guerin H. Sur les arseniates de nikel// Bull. Soc. Chim. France. 1959. №1. pp. 121.

[9] Beilina A.Z., Jumanova K.M., Muldakhmetiov Z.M., Khalitiva R.C. About physical-chemical properties of the main arsenates of copper //J. Physichesko khimii. 1977, v. 51, 2. pp. 480-482.

[10] Beilina A.Z., Jumanova K.M., Muldakhmetiov Z.M., Sargazina L.J. Investigations of arsenate compounds of copper, nickel, iron, titanium obtained in system $\mathrm{M}(\mathrm{OH}) \mathrm{n}-\mathrm{As} 2 \mathrm{O} 5-\mathrm{H} 2 \mathrm{O} / / \mathrm{Ximia}$ i texnologia coedinrnii Arsenic and antimony. Alma-Ata, 1980, pp. 80-89.

[11] Makhmetov M.J., Sagadieva A.K., Chuprakov V.N. Investigations of solubility of iron arsenate. //J. Prikladnoi Ximii. 1981, v.54. №5, pp. 1009-1011. 